\title{
Analysis and Evaluation of Interface Mechanics for Thin Films using the Method of Image
}

\author{
Chongyang NIE, Le GU, Dezhi ZHENG , Xiaoli ZHAO, and Liqin WANG \\ Harbin Institute of Technology, Research Lab of Space \& Aerospace Tribology, Hei Longjiang Province, Harbin 150001, China.
}

\begin{abstract}
The evaluation of interface mechanics was very useful for the design of thin solid film. According to the method of image, interface stresses and deformations of coating-substrate system were gained. Using this mathematical calculation model, the indentation test data was carried out and the results were analysed. Based on the mechanical model and test, the critical state of interface stresses from elastic deformation to plastic yield was evaluated. From experimental and calculating results, interface shear stress and normal stress had different affecting level for the coating failure under the same surface load. And a fitting relationship equation for the two stresses was also gained to determining the failure value in designing. The method of this paper could be used for thin film interface mechanics design and evaluation.
\end{abstract}

\section{Introduction}

Thin solid films or coatings are widely used as combining material in civil and industry applications, such as rolling bearings, gears, and many other mechanical components. With surface modified layers, these components behaved distinguished load carrying capacity, contact friction performance, and environmental adaptability.

Today many scholars researched and designed varying coatings for different applications and environments [1-3]. In high-speed, high-temperature, and heavy-load [4], as well as other extreme environments [5, 6], thin solid films were good solutions. And varies researches and designs were carried out for different coatings in different mechanical components [7], followed the interest of tribo-pairs with layered structure for their service life and reliability[8-10].

Nano indention and scratch were common tools for material mechanics tests. But these experiments were totally reliant on the test samples, instruments, environments, operations, and manipulators, so the results and criterions in these experiments were significantly diverse and impossible to compare with each other. Sometimes a conclusion from one test would even contradict the other ones found in different tests [11-13]. So a better understanding of indention data needed a mathematical model to evaluate interface stresses and deformations.
The analysis and evaluation of thin films interface could also be used for performance improvement and optimization with the aim of improving stress level in the substrates and enhancing bonding strength along the interface. Based on the analysis of interface mechanics $[14,15]$ in this paper, a coating-substrate system model was built using mathematical formulations, while the interface mechanics characteristics of diamond-like carbon (DLC) coating deposited on $\mathrm{Si}_{3} \mathrm{~N}_{4}$ ceramics were analysed and evaluated theoretically and experimentally.

\section{Theoretical analyses}

For a coating-substrate system, interface was a vital layer to connect the bi-materials, and its stresses and deformations were investigated in the following sections.

\subsection{Analytical model of coating-substrate system}

Thin solid film was deposited on an elastic half-space body as shown in Figure 1. The elastic modulus of coating $I$ and substrate $I I$ were defined as $E_{1}$ and $E_{2}$, Poisson's ratio $v_{1}$ and $v_{2}$, respectively. $h$ was the thickness of the coating and, as it was extremely thin in regards to the substrate, the latter was therefore considered as semiinfinite. From Figure 1, a pressure distribution was applied on the thin film surface which meant a Hertz's normal contact state $p(\eta)$ with tangential friction traction force $q(\eta)$. The total force was the integration of normal force and tangential traction along the surface coordinate. 


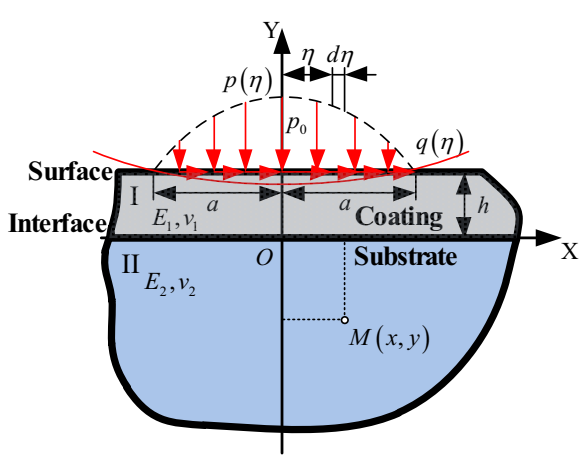

Figure 1. The model of coating-substrate system

From Figure 1, coating $I$ was used to cover the surface of substrate $I I$, connected only by the interface. Above the coating there was a free surface, and $X$-axis (real axis) was along the interface, and $Y$-axis (imaginary axis) was perpendicular with $X$-axis and passed through $O_{1}$. The two axes intersected at $O$, namely the global origin point and the reference frame $X O Y$.

\subsection{The method of image}

The interface stresses shown in Figure 2 could be calculated by the method of images from the complex variable function. The boundary conditions and the constraints of the model were equivalent; furthermore, equations were composed using the relationship between stress and strain. As the method of images, the interface and the surface were imagined as mirrors that reflected point $O$ or $O_{1}$ and that would generate infinite points of mirror images. These images influenced the interface stresses as a superposition form in order to maintain the boundary conditions and constraints. Namely, the conditions of interface continuum and free surface were satisfied and interface stresses were gained by superposing the stress solutions of these image points.

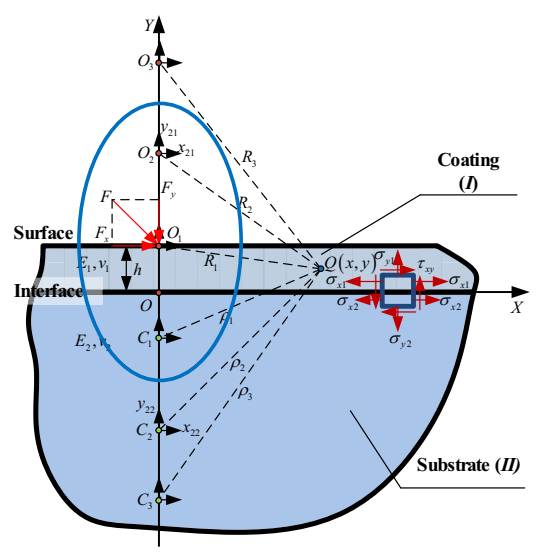

Figure 2. The scheme of the method of image

The complex interface and surface boundary condition were equation (1) and (2)

$$
\begin{gathered}
\sigma_{y I}+i \tau_{x y I}=\sigma_{y I I}+i \tau_{x y I I} \text { and } u_{I}+i v_{I}=u_{I I}+i v_{I I}, \text { for } y=0 \\
\sigma_{y I}+i \tau_{x y I}=0, \text { for } y=h
\end{gathered}
$$

Here subscript I and II denoted material I and II, respectively. $\sigma_{x}$ and $\sigma_{y}$ were stresses along $x$ and $y$ direction, $\tau_{x y}$ was the shear stress. $u$ and $v$ represented deformations along $x$ and $y$ direction.

The analysis proceduce was rather cumbersome, and the readers who have interest could referred literature [14] and [15] for details. Here the Green's functions for the relationship between stress and deformation were gave as following equations (3)-(8) .

$$
\begin{aligned}
& d \sigma_{y I}+i \tau_{x y I}=G_{1} z_{k}, s_{k}, \eta d \eta \\
& G_{1} z_{k}, s_{k}, \eta=\sum_{k=1}^{\infty}\left[\begin{array}{lll}
A_{k}^{\prime} & z_{k}-\eta+\Phi_{k}^{\prime} & s_{k}-\eta
\end{array}\right] \\
& +\sum_{k=1-}^{\infty}\left[\overline{A_{k}^{\prime}} z_{k}-\eta+\bar{\Phi}_{k}^{\prime} s_{k}-\eta\right] \\
& +\bar{z}-\eta \sum_{k=1}^{\infty}\left[A_{k}^{\prime \prime} z_{k}-\eta+\Phi_{k}^{\prime \prime} s_{k}-\eta\right] \\
& +\sum_{k=1}^{\infty}\left[B_{k}^{\prime} z_{k}-\eta+\Psi_{k}^{\prime} s_{k}-\eta\right] \\
& d \sigma_{x I}+\sigma_{y I}=G_{2} z_{k}, s_{k}, \eta d \eta \\
& G_{2} \quad z_{k}, s_{k}, \eta=4 \operatorname{Re}\left(\sum_{k=1}^{\infty}\left[A_{k}^{\prime} z_{k}-\eta+\Phi_{k}^{\prime} s_{k}-\eta\right]\right) \\
& 2 \mu_{I} d \quad u_{I}+i v_{I}=G_{3} z_{k}, s_{k}, \eta d \eta \\
& G_{3} \quad z_{k}, s_{k}, \eta=\kappa_{I} \sum_{k=1}^{\infty}\left[\begin{array}{llll}
A_{k} & z_{k}-\eta+\Phi_{k} & s_{k}-\eta
\end{array}\right]
\end{aligned}
$$

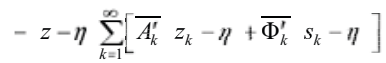

$$
\begin{aligned}
& -\sum_{k=1-}^{\infty}\left[\overline{B_{k}} z_{k}-\eta+\overline{\Psi_{k}} s_{k}-\eta\right] \\
& d \sigma_{y I I}+i \tau_{x y I I}=G_{4} z_{k}, s_{k}, \eta d \eta \\
& G_{4} z_{k}, s_{k}, \eta=\sum_{k=1}^{\infty} a_{k}^{\prime} z_{k}-\eta \\
& +\sum_{k=1}^{\infty} \overline{a_{k}^{\prime}} z_{k}-\eta \\
& +\bar{z}-\eta \sum_{k=1}^{\infty} a_{k}^{\prime \prime} z_{k}-\eta+\sum_{k=1}^{\infty} b_{k}^{\prime} z_{k}-\eta \\
& d \sigma_{x I I}+\sigma_{y I I}=G_{5} z_{k}, s_{k}, \eta d \eta \\
& G_{5} \quad z_{k}, s_{k}, \eta=4 \operatorname{Re}\left[\sum_{k=1}^{\infty} a_{k}^{\prime} z_{k}-\eta\right] \\
& 2 \mu_{I I} d u_{I I}+i v_{I I}=G_{6} \quad z_{k}, s_{k}, \eta d \eta \\
& G_{6} z_{k}, s_{k}, \eta=\kappa_{I I} \sum_{k=1}^{\infty} a_{k} z_{k}-\eta \\
& \text { - } z-\eta \sum_{k=1}^{\infty} \overline{a_{k}^{\prime}} z_{k}-\eta \\
& -\sum_{k=1}^{\infty} \overline{b_{k}} z_{k}-\eta
\end{aligned}
$$

\section{Experimental details}

The DLC coating was deposited on the surfaces of $\mathrm{Si}_{3} \mathrm{~N}_{4}$ ceramics by plasma based ion implantation (PBII) [13]. The disk samples were $\Phi 22 \mathrm{~mm} \times 3 \mathrm{~mm}$ with a surface roughness $\mathrm{Ra}$ 0.02-0.04 $\mu \mathrm{m}$ and had been previously ultrasonic cleaned for $5 \mathrm{~min}$ by acetone and anhydrous ethanol before thin film deposited onto the surfaces. The oxide and adsorbent on the samples' surface were removed by cathode deflection $\mathrm{Ar}+$ ion under 2-3 $\mathrm{mPa}$ vacuum for 5 minutes. Then, the chamber pressure was set to $1.5 \mathrm{~Pa}$ and filled with reactant $\mathrm{V}\left(\mathrm{C}_{2} \mathrm{H}_{2}\right): \mathrm{V}\left(\mathrm{H}_{2}\right)=10$ : 1. The period of deposition was for 3 hours using an 20 $\mathrm{mA}$ current and a voltage of $20 \mathrm{kV}$. 
Tested by the spectral photometer ETA-SST, the thickness of the DLC coating was $300 \mathrm{~nm}$. The loadcarrying ability of the DLC coating was measured using Nano-Indenter XP so that its curvature radius of the conical indenter was $0.99 \mu \mathrm{m}$.

Six experiments [14] were implemented on every sample. The load was applied at the increasing rate of 0.5 $\mathrm{mN} / \mu \mathrm{m}$ when the indenter made contact with the surface of the sample. The forces were recorded at the abrupt point of the penetration curves.

\section{Results and discussions}

Here based on the test data, interface stresses and deformations were calculated and discussed.

\subsection{Test results}

The penetration curves with the load increasing were shown in Figure 3 for different film thickness.

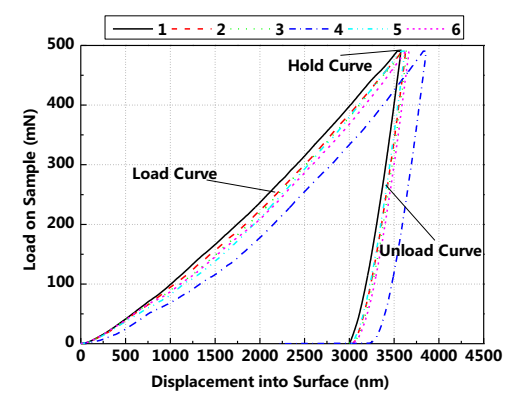

(a) The coating thickness of $110.6 \mathrm{~nm}$

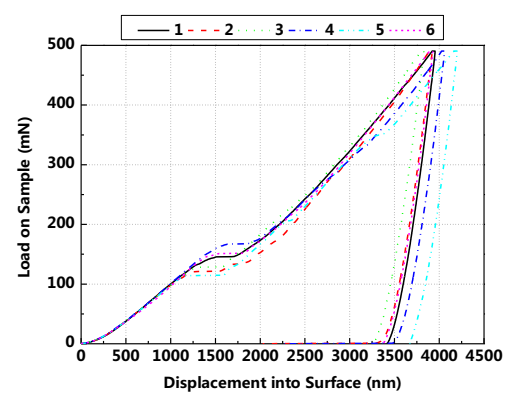

(b) The coating thickness of $381.8 \mathrm{~nm}$

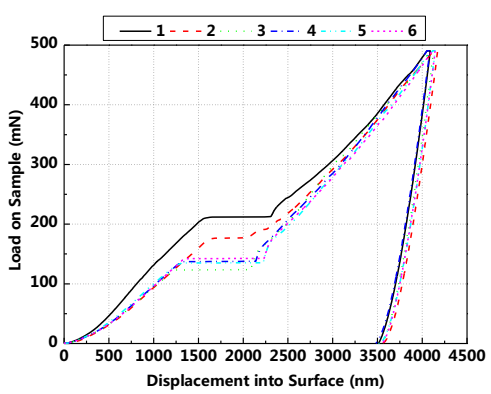

(c) The coating thickness of $763.8 \mathrm{~nm}$

Figure 3. The penetration curves with the load increasing in indention tests
From the curve trends Figure 3 (a) - (c), the thicker the coating was, the more distinct of the smooth curvature was.

After the indention tests, the penetration depth by the indenter normal movement and the contact load applied on it were recorded, the data was listed in Table 1 when the curvature of test load lines emerged a step, which meant the coating-substrate system underwent from elastic deformation to elastic-plastic deformation.

Table 1. Indentation test data

\begin{tabular}{|c|c|c|c|c|c|c|}
\hline \multirow{2}{*}{$\begin{array}{l}h(\mathrm{~nm}) \\
\text { No. }\end{array}$} & 110.6 & 381.8 & 763.8 & 110.6 & 381.8 & 763.8 \\
\hline & \multicolumn{3}{|c|}{ Depth (nm) } & \multicolumn{3}{|c|}{ Load $(m N)$} \\
\hline 1 & 764 & 1288 & 1562 & 72 & 132 & 210 \\
\hline 2 & 682 & 1233 & 1638 & 59 & 121 & 175 \\
\hline 3 & 751 & 1274 & 1241 & 65 & 128 & 123 \\
\hline 4 & 769 & 1637 & 1312 & 52 & 167 & 137 \\
\hline 5 & 745 & 1141 & 1314 & 60 & 113 & 135 \\
\hline 6 & 815 & 1281 & 1319 & 72 & 134 & 139 \\
\hline Ave. & 754 & 1309 & 1398 & 63 & 132 & 153 \\
\hline Dev. & 16 & 63 & 60 & 3 & 7 & 12 \\
\hline
\end{tabular}

\subsection{Analysis and evaluation}

Here using the mathematical model of section 2, interface stresses and deformations were calculated for different coating thicknesses. As shown in Figure 4, stresses and deformations were increased with the contact load, the thicker coating could carry a heavier load or a larger interface stress level before plastic deformation occurred.

From Figure 4 (a) to (c), if the thickness of coating was rather thin as $110.6 \mathrm{~nm}$, it plastically deformed easily than thicker ones. Though the critical loads and stresses level in thinner solid film were a little lower, when the thickness increasing, the limiting value of the stress was presence and the stress divergence between thickness $381.8 \mathrm{~nm}$ and $763.8 \mathrm{~nm}$ was already very approaching.

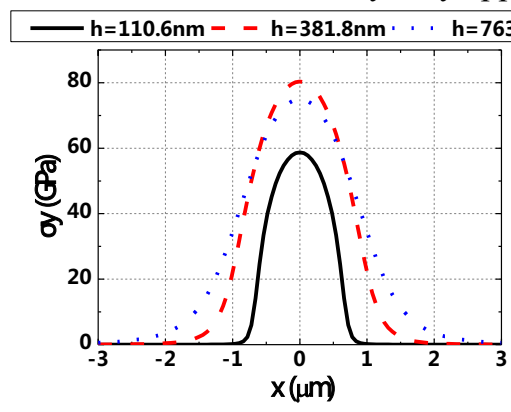

(a) Normal stresses along the interface

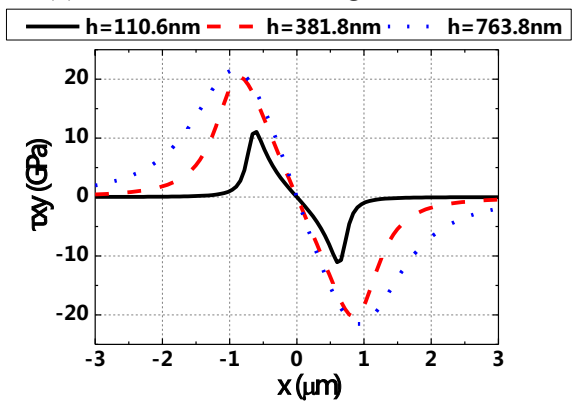

(b) Shear stresses along the interface 


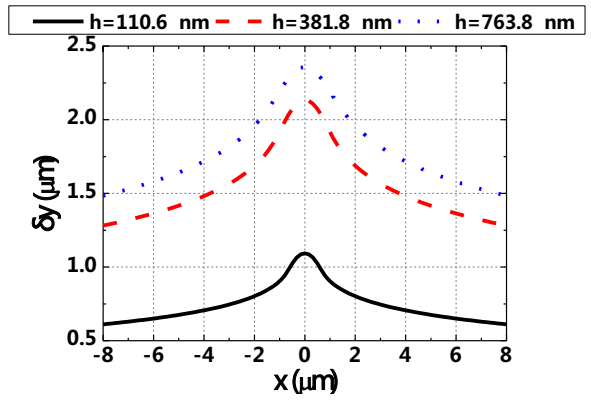

(c) Normal deformations along the interface

Figure 4. Calculating results of stresses and deformations for different coating thicknesses

About the failure mode of DLC coating, interface peeled off was similar with brittle material such as rocks. So Coulomb-Mohr criterion $[15,16]$ was used here for failure evaluation. The calculated maximum interface shear stresses and normal stresses were chosen from Figure 4 at the critical point of indention test. A fitting equation $\tau_{\max }=0.34857 \sigma_{y}-15.9873$ was gained by linear relationship as shown in Figure 5.

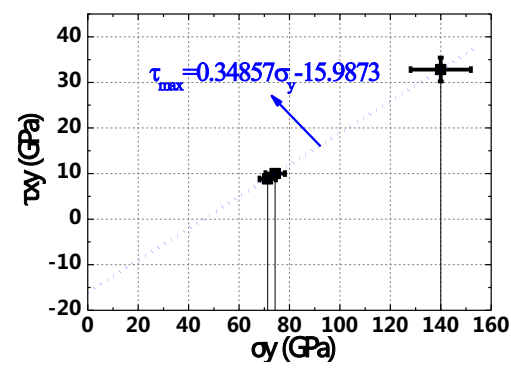

Figure 5. Fitting relationship between maximum shear stress and normal stress

The intercept of fitting line was $15.9873 \mathrm{GPa}$ with $Y$ axis, and the shear bond strength of the interface could represent by this value $[15,16]$. This critical value could be the plastic failure stress of coating-substrate system for coating design. From the fitting equation we found that the influence level of interface carrying capacity by tensile stress and compression stress was different.

\section{Conclusions}

Interface stresses and deformations of coating-substrate system were calculated by the method of image. According to the indentation test, the experimental data was analysed using this mathematical calculation model, and the interface critical state from elastic deformation to plastic deformation was evaluated.

From experimental and calculating results, interface shear stress and normal stress were in different level for interface failure under the same surface load. The analytical and evaluative method here could be used for thin film interface mechanics design and evaluation.

\section{Acknowledgements}

This research is supported by Major State Basic Research Development Program (973) (2013CB632305) and the National Natural Science Foundation of China (51475452 and 51275125). Thanks for the testing works from Cuini Jing.

\section{References}

1. K. Holmberg, A. Laukkanen, E. Turunen, and T. Laitinen, Wear resistance optimisation of composite coatings by computational microstructural modelling, Surface and Coatings Technology, 247, pp. 1-13, 5/25/ 2014.

2. A. Ghabchi, S. Sampath, K. Holmberg, and T. Varis, Damage mechanisms and cracking behavior of thermal sprayed $\mathrm{WC}-\mathrm{CoCr}$ coating under scratch testing, Wear, 313, 97-105, 5/15/ 2014.

3. J. C. Avelar-Batista Wilson, S. Banfield, J. Eichler, A. Leyland, A. Matthews, and J. Housden, An investigation into the tribological performance of Physical Vapour Deposition (PVD) coatings on high thermal conductivity $\mathrm{Cu}$-alloy substrates and the effect of an intermediate electroless $\mathrm{Ni}-\mathrm{P}$ layer prior to PVD treatment, Thin Solid Films, 520, 2922-2931, 1/31/ 2012.

4. Y. Alinia, M. A. Guler, and S. Adibnazari, On the contact mechanics of a rolling cylinder on a graded coating. Part 1: Analytical formulation, Mechanics of Materials, 68, 207-216, 1// 2014.

5. S. B. Weber, H. L. Lein, T. Grande, and M. A. Einarsrud, Influence of the precursor solution chemistry on the deposition of thick coatings by spray pyrolysis, Surface and Coatings Technology, 221, 53-58, 2013.

6. M. A. Guler, Y. Alinia, and S. Adibnazari, On the contact mechanics of a rolling cylinder on a graded coating. Part 2: Numerical results, Mechanics of Materials, 66, 134-159, 11// 2013.

7. X. Zhang and B. L. Weeks, Effects on the surface structure of organic energetic materials using spin coating, Thin Solid Films, 550, 135-139, 2014.

8. J. Scheibert, A. Prevost, G. Debrégeas, E. Katzav, and M. Adda-Bedia, Stress field at a sliding frictional contact: Experiments and calculations, Journal of the Mechanics and Physics of Solids, 57, 1921-1933, 12// 2009.

9. R. Hauert, K. Thorwarth, and G. Thorwarth, An overview on diamond-like carbon coatings in medical applications, Surface and Coatings Technology, 233, 119-130, 10/25/ 2013.

10. K. Holmberg, A. Laukkanen, H. Ronkainen, and K. Wallin, Surface stresses in coated steel surfacesinfluence of a bond layer on surface fracture, Tribology International, 42, 137-148, 1// 2009.

11. T. P. Nowak, L. J. Jankowski, and J. JasieŃKo, Application of photoelastic coating technique in tests of solid wooden beams reinforced with CFRP strips, Archives of Civil and Mechanical Engineering, 10, 53-66, // 2010. 
12. H. S. Park and D. Kwon, An energy approach to quantification of adhesion strength from critical loads in scratch tests, Thin Solid Films, 307, 156-162, 10/10/ 1997.

13. C. N. Jing, L. Gu, Ch. W. Zhang, G. Z. Tang, L. Q. Wang, Preparation and tribological properties research of DLC film on the surface of $\mathrm{Si}_{3} \mathrm{~N}_{4}$ ceramics, 35, 9, Lubr. Eng. Sept. (2010) 21-25.

14. C. NIE, D. ZHENG, L. GU, X. ZHAO, L. WANG, Comparison of interface mechanics characteristics of DLC coating deposited on bearing steel and ceramics, Applied Surface Science, 317, 188-197, (2014).

15. J. Q. Xu, Interface mechanics, Science Press, Beijing, 2006.

16. Z. Y. ZHANG \& J. Q. XU, The interface failure criterion of coating materials, Journal of Shanghai Jiaotong University. pp. 983-987, 2007. 